\title{
Non-destructive ultrasonic tomography for concrete pavement evaluation: signal processing and image analysis of crucial parameters
}

\section{Tomografia ultrassônica não destrutiva para avaliação de pavimentos de concreto: processamento de sinal e análise de imagem de parâmetros cruciais}
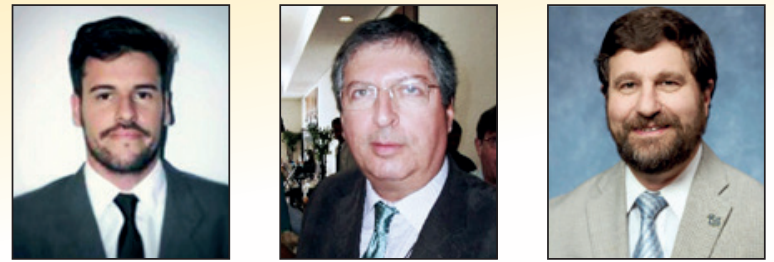

L. S. SALLES lucio.salles@usp.br

J. T. BALBO a jotbalbo@usp.br

L. KHAZANOVICH khaza001@umn.edu

\section{Abstract}

In recent years, due to the destructive and unproductive character of pavement specimen extraction, pavement maintenance technology intensified the use of non-destructive techniques for pavement evaluation which resulted in the development of several devices and evaluation methods. This paper describes the use of technology based on low frequency ultrasonic tomography for evaluation of concrete pavement parameters. The equipment was applied in three experimental sections with different concrete pavements built at the University of Sao Paulo campus. The ultrasonic signal processing is given. The results analysis enables the efficient and reliable identification of thickness and reinforcement position within the concrete slab. Construction problems were evidenced in one of experimental sections with thickness deficiencies and reinforcement in a position below projected. Furthermore, the use of a novel concrete quality indicator was correlated with the presence of transverse cracks and alkali-silica reaction within the sections.

Keywords: concrete pavements, non-destructive evaluation, ultrasonic tomography, slab thickness, distresses.

\section{Resumo}

Recentemente, devido ao caráter destrutivo e pouco produtivo de extrações de material de pavimentos em operação, a tecnologia de manutenção de pavimentos intensificou a utilização de técnicas não destrutivas para avaliação de pavimentos o que resultou no desenvolvimento de vários equipamentos e métodos de avaliação. Este artigo descreve a aplicação de tecnologia baseada em tomografia ultrassônica de baixa frequência para avaliação de parâmetros em pavimentos de concreto. O equipamento foi aplicado em três seções experimentais com diferentes tipos de pavimentos de concreto construídas no campus da Universidade de São Paulo. O processamento de sinal é apresentado. A análise de resultados permite a identificação eficaz e confiável da espessura da placa de concreto e da posição da armadura. Problemas construtivos foram evidenciados em uma das seções experimentais apresentando deficiências de espessura de placa e armadura posicionada abaixo da cota de projeto. Ademais, a utilização de um novo indicador de qualidade do concreto foi correlacionada com a presença de fissuras transversais e reação álcali-agregado nas seções estudadas.

Palavras-chave: pavimentos de concreto, avaliação não destrutiva, tomografia ultrasônica, espessura de placa, defeitos. 


\section{Introduction}

Non-destructive evaluation methodologies are structural analysis techniques in which it is not necessary to physically examine the material. It is possible to observe various parameters within the material without actually having contact with its inside. The biggest advantage of this type of study is clearly the not harmful evaluation character. For pavements, one of the major problems found in layers analysis and characterization is the great heterogeneity of the material. A single location extraction may not be representative of the whole structure. Additionally, specimen extraction or trenching the pavement may cause a higher or lesser degree of damage. The replacement of the removed material will certainly not present the same properties as the original layer. Furthermore, the extraction vicinities are known potential origins of distresses such as cracks and faulting because the stress configuration in such points is not the same as the continuous structure. Adhesion problems between the recomposed material and the original layer aggravate this issue. In addition to the structural details, material forensic extraction is costly, laborious, unproductive and potentially not representative of the structure as a whole, again regarding the heterogeneity topic (Grote et al., 2005 [1]).

Currently, the combined use of destructive and non-destructive techniques has become the primary means of road structure evaluation. Firstly, a non-destructive device is applied in a comprehensive and rapid assessment of the pavement. After the data interpretation, locations with distresses or where there is doubt on the device's results receive a more in-depth study with potential material extraction. As, commonly, pavement structures extend for several kilometers, the combination of methods seems to be the key point in the postconstruction assessment (thickness check, presence and positioning of steel bars, early-age distresses, etc.) and in the maintenance feasibility studies (distresses, the presence of water, voids, etc.). In addition to these tasks, unlike the destructive procedures, nondestructive methods can be quality control tools during construction and not only instruments for assessing distress and/or maintenance and rehabilitation measures. Moreover, distress inspection without causing further damage or destruction of the layer can greatly assist maintenance decisions, such as whether or not to perform a partial or full repair (Hoegh et al. [2]).

The main goal of this paper is the use of nondestructive tomography technology to analyze very relevant aspects of pavement concrete structures related to performance and deterioration. Direct comparison of thicknesses by cored samples and non-destructive testing are presented; locations presenting transverse cracks and alkali-silica reaction (ASR) were sought by tomography image reconstruction and signal interpretation. The data processing of the ultrasonic tomography device (MIRA) procedure is also presented. The ultrasonic testing was performed in experimental concrete pavements located at the University of São Paulo main campus.

\section{Modern non-destructive evaluation methods for concrete pavements}

Non-destructive methods, if properly performed and interpreted, can quickly evaluate a specific point without damaging it. However, one should be aware that all methodologies have simplifica- tions which can lead to disastrous results. In this section, the most modern methods of non-destructive evaluation are discussed with emphasis on quality, flaws and limitations.

\subsection{Ground Penetrating Radar (GPR)}

GRP can be equipped with sending and registering antennas with different frequency. By using high frequency antennas, the results appear in high resolution, though the depth ranges are low. Conversely, low frequency antennas provide deeper penetration with the cost of a lower resolution. Most commercial GPR provide antennas with frequencies between $50 \mathrm{MHz}$ and $1.5 \mathrm{GHz}$ (Daniels [3]). The primary GPR evaluative function for pavements was to determine thickness of both asphaltic and concrete layers (Tompkins et al. [4]). The possibility of performing surveys with GPR equipment coupled to a vehicle allows this this type of evaluation to be very productive, making it almost continuous, with minimal traffic interruption (Olhoeft and Smith III [5])

GPR calibration is usually done with the use of a concrete specimen comparing the travel time with the exact specimen thickness (Hugenschmidt [6]). In the mentioned study, the observed error between the measured thickness of the concrete specimen and the thickness determined by GPR was between 50 and $150 \mathrm{~mm}$; what the author regards as an acceptable error margin. It should be noted that other studies found major errors due to inaccurate estimates of the dielectric constant, which intensifies the need for a thorough study of this parameter (Grote et al., 2005 [1]). For bridges, a study was able to correctly measure the concrete cover of $77 \%$ of the cases inspected. The average difference between GRP results and the actual data was $10 \mathrm{~mm}$. For concrete thickness, $95 \%$ of the measurements were successful ( $9 \mathrm{~mm}$ average error) (Hugenschimdt and Mastrangelo [7]).

However, despite the results discussed, several studies point out difficulties and flaws in the GPR evaluation. A 2012 study reports that the GPR returns mostly accurate information but only for small thicknesses; according to the authors the extent to which the evaluation deepens, the readings become less accurate. Furthermore, the visualization of non-uniform cracks is difficult (Hoegh et al. [2]). Others also point out issues in observation of voids and cracks with GPR (Haza et al. [8]). Moreover, when the moisture level is too high, the electromagnetic waves are absorbed rapidly losing potential. Consequently, it is practically impossible to investigate fresh concrete or in the early stages of curing (Maierhofer [9]). Due to concrete's mitigation effect on the GPR waves, data regarding base and sub-base layers are lost, which does not occur in asphalt pavements. This indicates that if strong reflections appear below the slab, the distress level or compromised area is quite alarming. Still, according to the same author, in some places, strong reflections have not resulted in areas with water, but clays or saturated bases without voids. This compromises the method, requiring destructive verification to certify the distress (Scullion, [10]).

\subsection{Infrared tomography}

Most materials absorb infrared radiation which causes a temperature increase. Moreover, all objects with temperature above absolute zero emit infrared energy. For this thermal-data to be 
visible and understandable, the technique of thermal-imaging is used to convert this pattern of thermal radiation to a visual image. To this end, an infrared camera is applied. Noteworthy advantages include no direct contact required with the object being analyzed, high productivity readings (rapid response), high resolution and portability (camera) (Clark et al. [11]).

However, infrared evaluations are dependent on several factors such as material temperature, atmospheric temperature and climate conditions. According to the previously mentioned authors, the effects of sunlight more clearly highlight objects which increase their temperature, improving the results. However, sunlight may also affect the infrared techniques masking the real material temperature (Park et al. [12]). Another study, while highlighting the technique successful potential to find delaminations in concrete, yields attention to the interference of climate conditions in the results (Hoegh and Khazanovich, [13]). Furthermore, the temperature influence on the readings is much more concise on the material surface, thus deeper assessments are difficult to interpret (Hoegh et al. [2]).

Adding to the infrared tomography disadvantages, one must know that when it is desired to know the object's temperature, the measurements are a combination of the object temperature and the temperature emitted by the object. Therefore materials that transmit more heat can influence the temperature of adjacent materials.

\subsection{Magnetic tomography}

Magnetic tomography is an evaluation technique that uses pulse induction principles to find metal parts within these objects. In the case of pavements, the Magnetic Imaging Tools (MIT Scan 2) is often used to check the positioning of dowel and tie bars. The device emits a pulsing magnetic signal of low intensity and measures the transient signal induced in the steel bars inside the concrete. These signals contain information on the electrical conductivity distribution and magnetic properties, which further allows for determining the position, size, shape, orientation and type of the metal body.

Despite the device's effectiveness in detecting metal elements in the structure (Prabhu et al. [14]), its use is limited to this type of material. For thickness estimation the placing of a metal plate is required at the base top for each measuring point (Nasief et al. [15]). Also, a 2006 study observed points that showed disagreement with real data, with great bar misalignments that did not occur according to forensic investigation. This, according to the authors, was due to the fact that the MIT Scan 2 readings are greatly influenced by the presence of other metal materials uncalibrated in the experiment near the analysis site (Hossain and Elfino [16]).

\subsection{Ultrasonic tomography}

Ultrasonic techniques apply high frequency waves (greater than $20,000 \mathrm{~Hz}$ ) to characterize the properties of materials and detecting distresses. Sound waves, generated by transducers, travel through the material being studied and are then received by receptors on the surface. Signal analysis allows discovering information about the means by which the signal has traveled. This technique has been used successfully for many years in medicine and evaluation of metallic and composite materials. In concrete materials, ultrasonic testing has been used for detection of inclusions, estimation of compressive strength and elastic modulus in concrete specimens (Perlin and Pinto [17]; Carnonari et al. [18]; Diogenes et al. [19]). However, most methods require the coupling of transducers and sensors in at least both sides of the specimen which is not applicable for pavement layers. Also, application of ultrasonic methods in typical pavement materials such as concrete

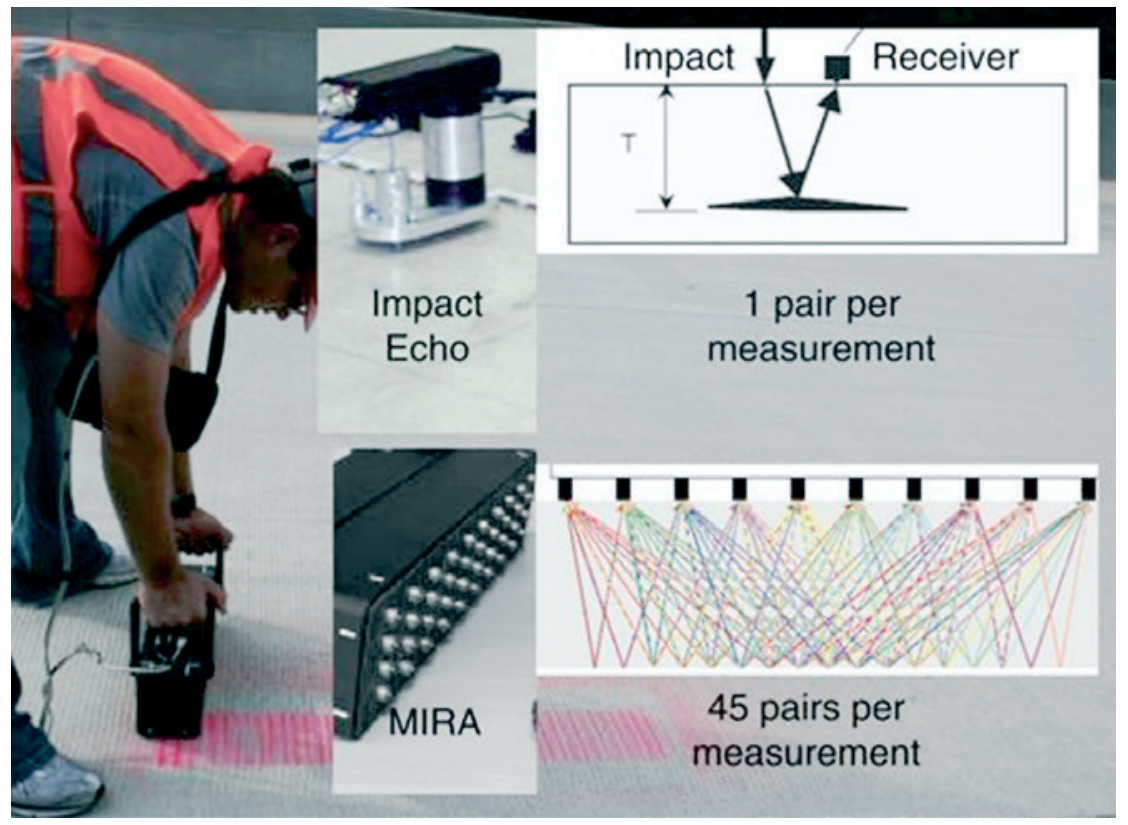

\section{Figure 1}

Impact echo versus MIRA (Hoegh et al., 2012[2]) 
and asphalt has been problematic due to the need for a coupling liquid and the difficulty in reaching the required thickness, because of the different layers which causes wave attenuation (Hoegh et al. [20] 2011). These difficulties led to the use of rudimentary methods such as chain dragging and impact echo. However, the former is much influenced by the operator and the second only correctly evaluates flat and uniform structures and distresses being both slow and unproductive (Hoegh and Khazanovich, [13]).

To overcome these problems, dry contact point transducers with the ability to send shear waves of low frequency $(55 \mathrm{kHz})$ allowing the effective penetration at greater depths were created. MIRA, one example of such device, has 45 pairs of transducers and receivers. A survey takes less than 2 seconds and results in a $2 \mathrm{D}$ image area. The great amount of data is interesting so that there is a perfect image compilation, especially for very heterogeneous materials. Low frequency waves (typically $50 \mathrm{kHz}$ ) allow the signal to navigate through the concrete despite the material heterogeneous characteristics. The signals are always reflected when an acoustic discontinuity takes place, which is defined as the interface between a medium wherein the impedance of the following medium is different. The acoustic impedance is a material property and is the product of sound velocity and material density (Vancura et al. [21]). Figure 1 shows the device and compares its operating principle to the impact echo.

A high correlation between MIRA and specimens extracted in situ for concrete cover and slab thickness was observed (Hoegh et al. [10]). A combination of various studies certify the sensitivity of MIRA with a correlation index of 0.9968 between specimen thicknesses and thickness measurements with MIRA (Vancura et al. [21]). Regarding distresses in comparison with other methods, ultrasonic evaluation with MIRA showed the best correlation with the destructive forensic studies showing the distress location and its depth (Hoegh et al. [22]).

\section{Processing of ultrasonic signals}

Data obtained from MIRA were processed with the technique developed by Hoegh et al. (Hoegh et al. [20]). Briefly, ultrasonic timehistory data provided by 10 transducers are processed using the synthetic aperture focusing technique (SAFT) that is based on the instantaneous amplitude of the readings. The information received by the transducer pairs ( 45 pairs) located at different spacing allows the reconstruction of the region of interest (ROI) reflectivity creating an image (B-Scan) through equations 1 and 2:

$\hat{\mathrm{o}}_{i, k}=\sum_{e=1}^{T-1} \sum_{r=e+1}^{T} A\left(x_{r}, x_{e}, x_{i}, z_{k}\right) \Psi_{e, r}\left(x_{i}, z_{k}\right)$

$\Psi_{e, r}\left(x_{i}, z_{k}\right)=s_{t}\left[x_{r}, x_{e}, \frac{1}{V}\left(\sqrt{z_{k}^{2}+\left(x_{i}-x_{e}\right)^{2}}+\sqrt{z_{k}^{2}+\left(x_{i}-x_{r}\right)^{2}}\right)\right]$

Where,

$\hat{o}_{i, k}=$ the image reflectivity of each position inside the ROI;

$\mathrm{T}=$ number of transducers positions;

$\mathrm{e}, \mathrm{r}=$ index of the emitting and receiving transducers;

$\mathrm{V}=$ shear wave velocity;

$\mathrm{i}, \mathrm{k}=$ index of the ROl's horizontal and vertical positions;
$\mathrm{S}_{\mathrm{t}}=$ the response magnitude at the evaluated time for given transducers;

$A=$ apodization coefficient, which is related to the various incident angles of the signal

The shear wave velocity is determined through the pulse-time data by knowing the spacing between the transducers and the time of the direct pulse arrival. Equation 3 can be applied in redundant information provided by the 45 signal pairs.

$V=\frac{\left(x_{i j}-x_{i k}\right)}{\left(t_{i, j}-t_{i k}\right)}$

Where $\mathrm{V}$ is the calculated shear wave velocity, $\mathrm{i}, \mathrm{j}$ and $\mathrm{k}$ are the transducers 1 through $10, x$ is the distance between transducers $i, j$ and $\mathrm{k}$ and $\mathrm{t}$ is the time of the direct arrival pulse for the time history related to transducers $\mathrm{i}, \mathrm{j}$ and $\mathrm{k}$.

When plotting all xi,j values and ti,j the linear trend line shows the actual shear wave velocity. The delay time can be removed from all points because it is a constant for all transducers. Figure 2 shows an example of this calculation. In this case the shear wave velocity is $2.739 \mathrm{~m} / \mathrm{ms}$.

As the survey amplitude with MIRA has limitations (each survey measures approximatively $360 \mathrm{~mm}$ ), a technique of combination of several consecutive B-Scans into a single panoramic image (SAFT-Pan) was created (Hoegh and Khazanovich [23]).

Furthermore, the analysis of the 45 signs in each survey allows the determination of a concrete quality indicator. Researchers comparing sound concrete with slabs with freeze-thaw distresses developed the Hilbert Transform Indicator (HTI) that was able to characterize the quality of the ultrasonic signal (Freeseman et al [24]). The indicator calculation is provided by Equation 4:

$H T I=\int_{0}^{500} \frac{H T(t)}{\max (H T(t))} d t$

where $\mathrm{HT}(\mathrm{t})$ is the signal envelope of the Hilbert transform that is analyzed for the first 500 us of signal time (enough to capture the pulse of the first arrival and to the signal to travel through the specimen). The HTI was also successfully used to show alkali-silica reaction related distresses (Dwight et al. [25]). For the two studies cited above, $\mathrm{HTI}$ above 90 indicated the presence of some damage level.

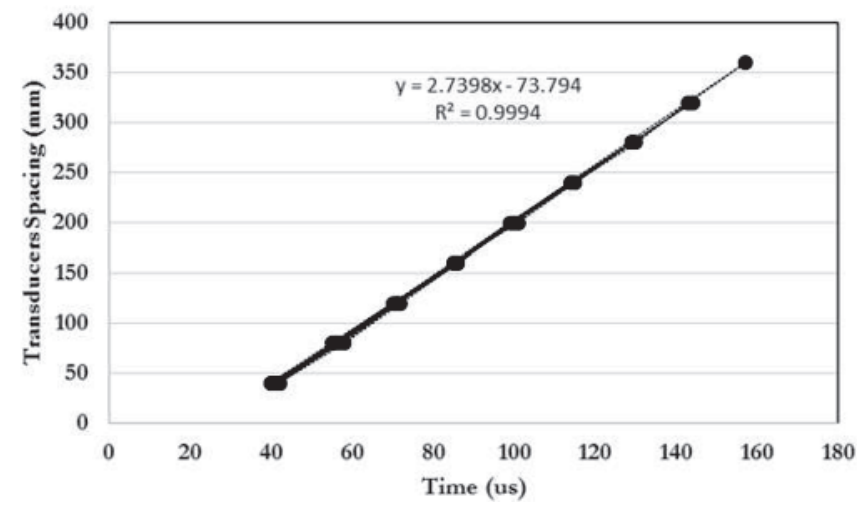

Figure 2

Shear wave velocity determination for the ultra-thin whitetopping 


\section{Analysis of parameters in different concrete pavement structures}

The ultrasonic survey was performed in three experimental pavement sections located at the campus of the University of São Paulo. The experimental sections are: (I) a parking lot with jointed-plain concrete pavement (JPCP) with slab thickness of 150 and 250 $\mathrm{mm}$, (II) a ultra-thin whitetopping (WTU) with a $100 \mathrm{~mm}$ thickness located at a bus stop and (III) a continuously reinforced concrete

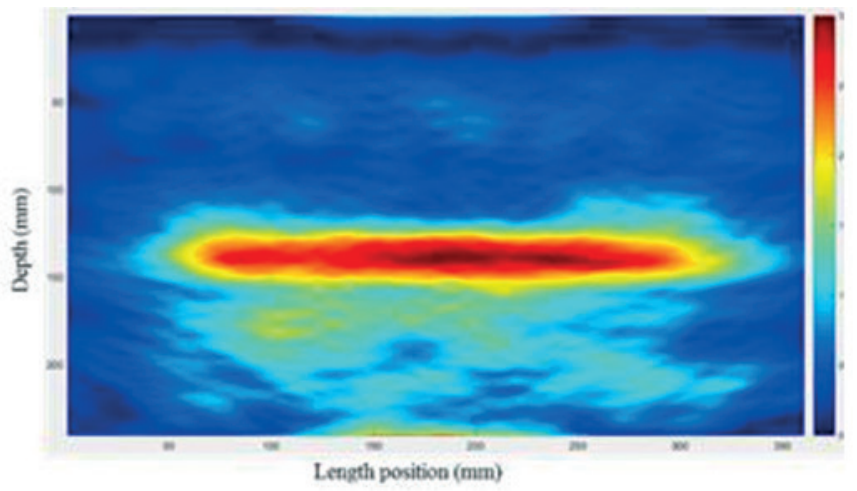

A JPCP - $135,00 \mathrm{~mm}$

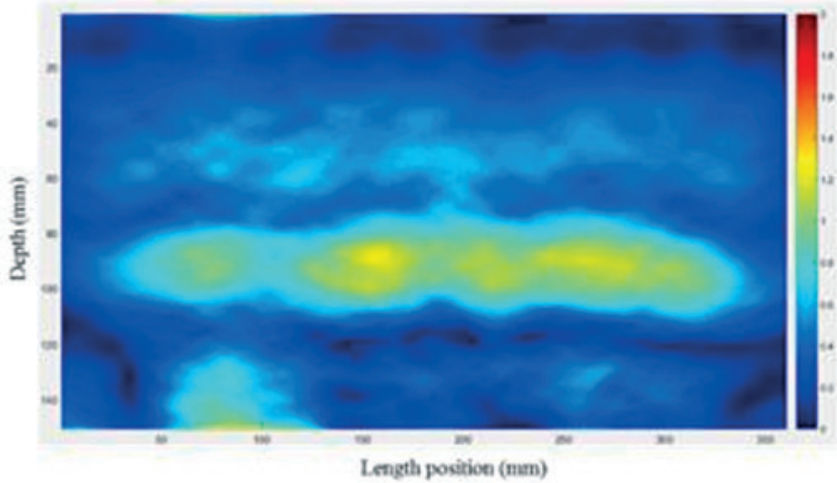

C UTW $-98,40 \mathrm{~mm}$

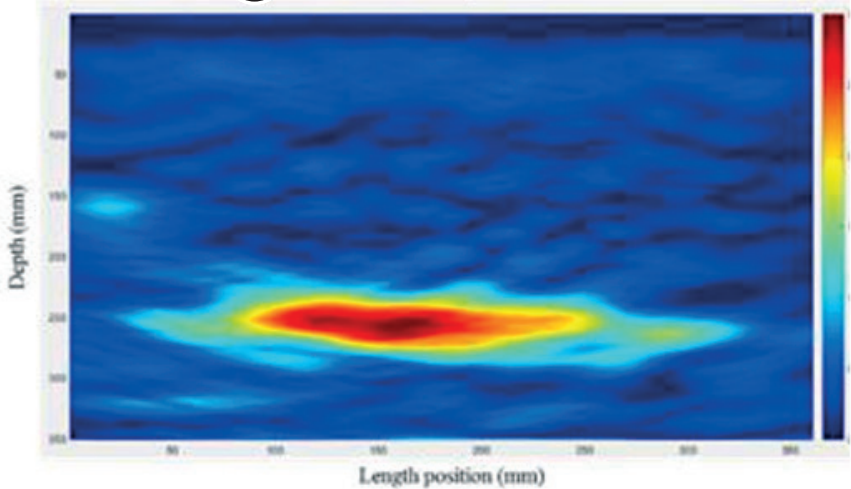

E CRCP - 244,00 mm pavement (CRCP) with a $240 \mathrm{~mm}$ thick slab located on an avenue. Constructive data and structural analysis on these three pavements can be found in Balbo and Severi [26], Balbo and Pereira [27] and Salles et al. [28], respectively.

\subsection{Concrete slab thickness}

In order to identify the division between two materials (two layers), the higher level reflection captured by the ultrasound (higher signal amplitude) is considered. As the concrete slab and the base material

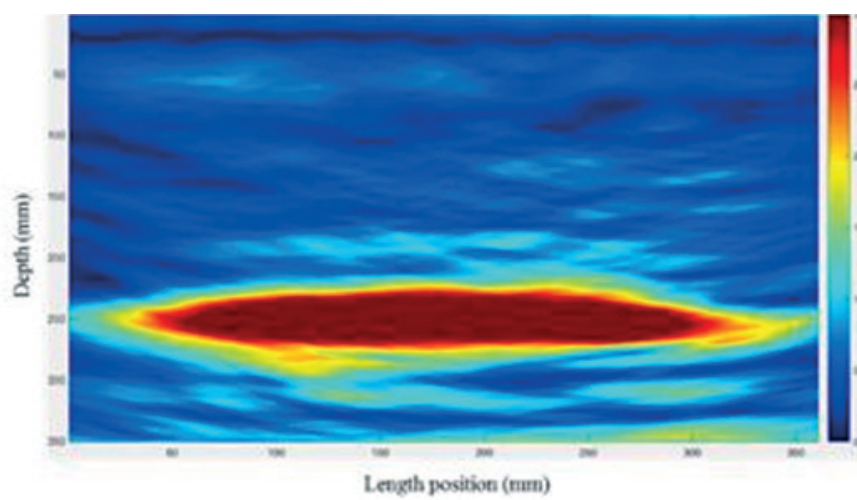

B JPCP - 238,77 mm

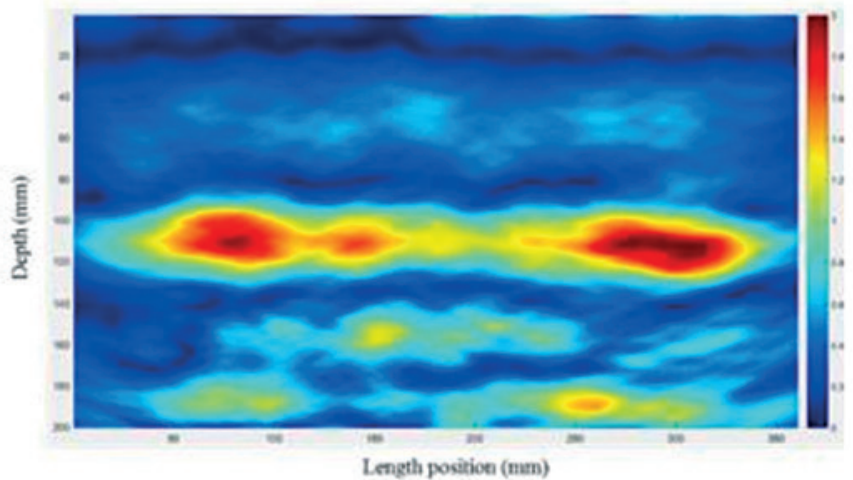

D UTW - 98,27 mm

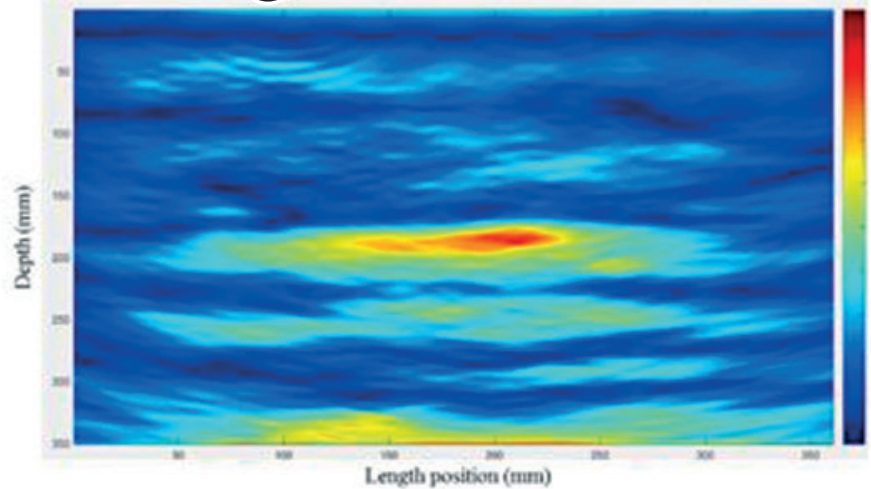

F CRCP - 184,10 mm

\section{Figure 3}

Thickness surveys reconstructions in concrete slabs with designed thickness of (a) $150 \mathrm{~mm}$; (b) $250 \mathrm{~mm}$; (c) and (d) $100 \mathrm{~mm}$; and (e) and (f) $240 \mathrm{~mm}$ 
have different properties, it is expected that the shear wave velocity in these mediums will be different. The simplicity of pavement structure geometry also helps in the identification of such reflections. Figure 3 shows some cases of B-Scans for thickness determination. In Figure 3, the delineation between slab and base is represented by a reflection line differing from the B-scan remain. The most perfect representation of the interface between slab and base would be a continuous line as shown by Figure 3b. However, several factors such as calibration, concrete heterogeneity, micro cracks and slab-base adhesion can modify the signal shape and strength. The signal attenuation is clear in Figures $3 \mathrm{c}$ and $3 \mathrm{~d}$ for the WTU. Note that the reflection intensity (bar located on the right side of the $B$ Scans) has a maximum peak of 2 for the WTU, while for the JPCP the peak value is the standard 3 . Reflections on a smaller scale show more details of the B-SCAN. This scale increase is necessary to better visualize the interface line. It is assumed that due to the WTU slab being completely adhered to the base layer (asphalt), the ultrasound signal suffers less attenuation than in other cases where the concrete slab is not bounded to the base. Most WTU B-scans show cases similar to Figure 3c, with only three cases having a greater interface reflection as in Figure 3d. This may be an indication of adhesion loss in the latter case. MIRA was applied to identify adhesion loss between two asphalt layers with (Hoegh et al. [29]). In the case of Figure $3 f$ (also with enlarged reflectivity scale of 2), it is possible to visualize a higher level of noise above the interface. These attenuations can result from minor distresses, segregation of coarse aggregates or problems in measurement calibration. However, for all cases it was possible to measure the highest value of the reflection signal disclosing its depth. This value (located below each B-Scan) is considered the thickness of the each slab. Reflections below the slab/base interface should not be considered because the device calibration only takes into account the first layer (concrete) being of little use for the analysis of layers below it.

The WTU thickness is substantially equal to the designed thickness. However, for the JPCP and especially for the CRCP, major variations were found. The first had a slab thickness about $15 \mathrm{~mm}$ thinner than the project. The CRCP presents a case (Figure 3e) slightly thicker than the project thickness and other well below it (Figure 3f). Specimens were removed in both positions (Figure 4) with a thickness of 240.6 for the first case and 190.1 for the second

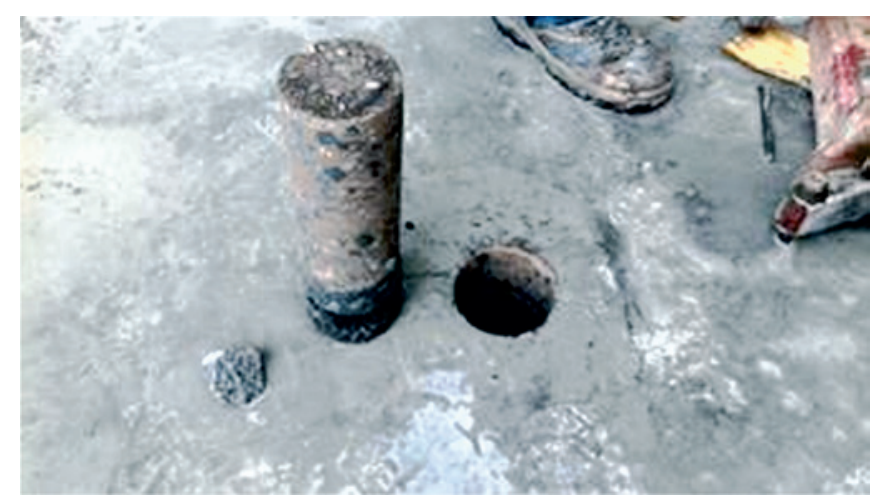

\section{Figure 4}

Forensic extraction of CRCP slab specimen case. The forensic extractions confirm the method accuracy showing error variation around $5 \mathrm{~mm}$, consistent with that found in the technical literature (Edwards [30]).

\subsection{Reinforcement}

Alterations in the acoustic impedance within the material are automatically recorded by the analytical process described above. As the bar's geometry is commonly known, the reinforcement identification is quite simple. Figure 5 shows B-Scans reconstructions of CRCP reinforcement. Typically, the signal amplitude on the interface between slab and base is greater than the reinforcement amplitude explaining the former greater level of reflection. Interface reflection breaks (Figure b) or weakening (Figures $5 b$ and $5 c$ ) are also expected right below the reinforcement due to loss or attenuation of the ultrasonic signal in that region. This evaluation is important to verify important aspects of the structure as reinforcement existence, depth and spacing. For the CRCP, the investigation found that in several cases the reinforcement was positioned below the steel depth indicated by the project, showing another constructive problem in this experimental section. The steel depth/ thickness ratio was designed at 0.42 , however, thickness deficiencies coupled with steel bars misplacement made the as built ratio to be 0.55 .

\subsection{Distresses}

Aside from thickness and reinforcement reconstructions, most of the common concrete pavement distresses do not have a known geometry in both size and shape making the distress identification more complex. Thus, two reconstruction features are the main focus: unexpected reflections above the slab/base interface (Figure $6 a-d)$ and/or breakage at the same interface (Figure $6 \mathrm{~b}$ and c). As evidenced with the reinforcement in the previous item, inclusions above the interface induce a loss of signal amplitude when the signal reaches the interface. In Figure 6, four cases of distress being two transverse cracks in the CRCP and two alkali-silica reaction (ASR) in the JPCP are presented. It is possible to observe a great difference between the reconstructions shown in Figure 6 and in Figures 3 and 5. Due to changes in the concrete homogeneity (voids, delaminations and degradation of the cement paste), the

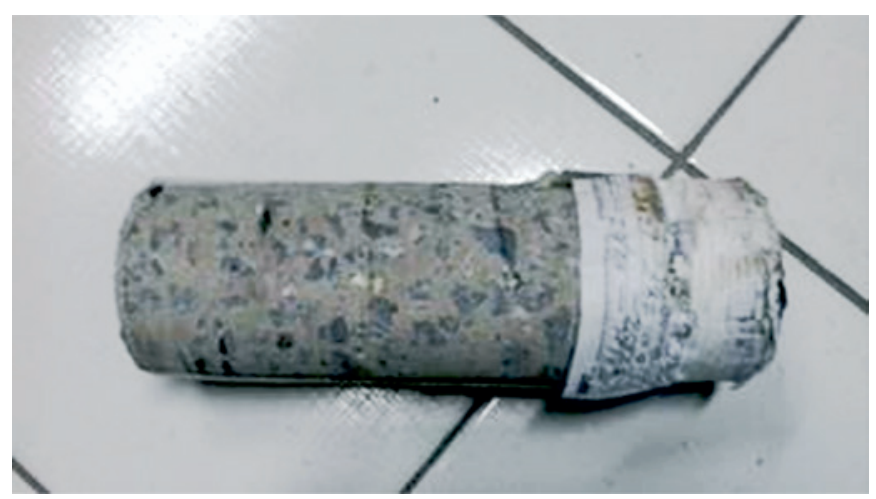




\section{Non-destructive ultrasonic tomography for concrete pavement evaluation: signal processing and image}

analysis of crucial parameters

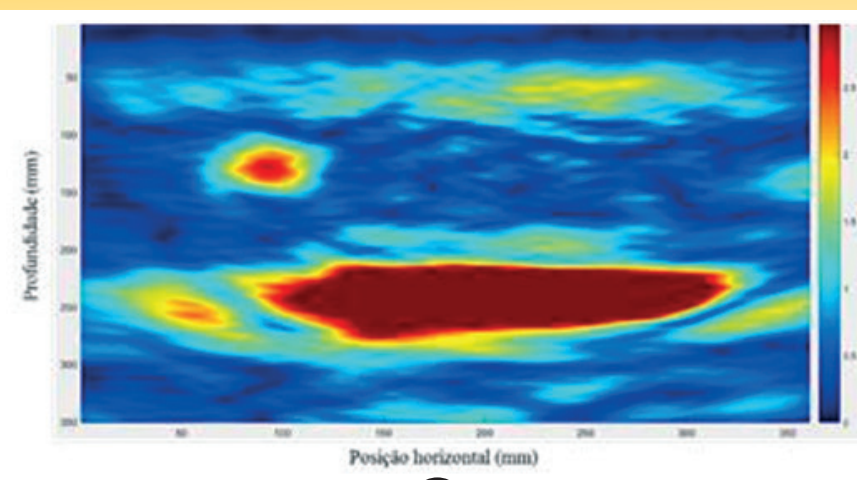

A

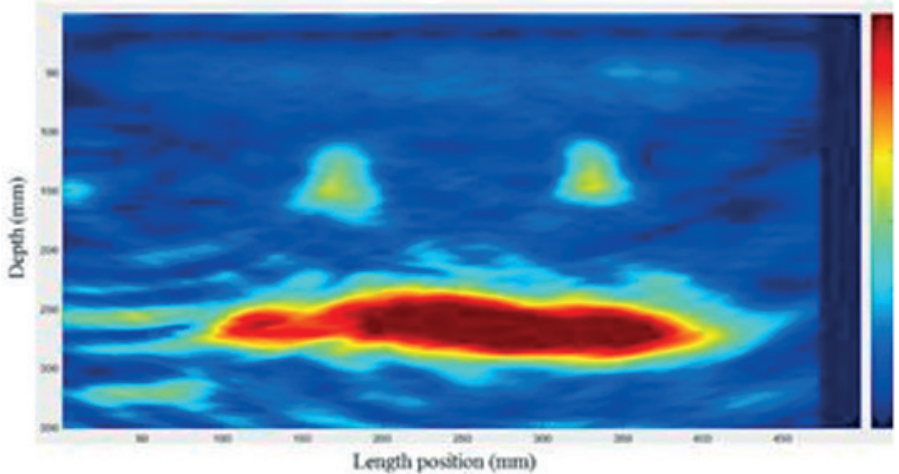

C

Figure 5

CRCP reinforcement reconstructions

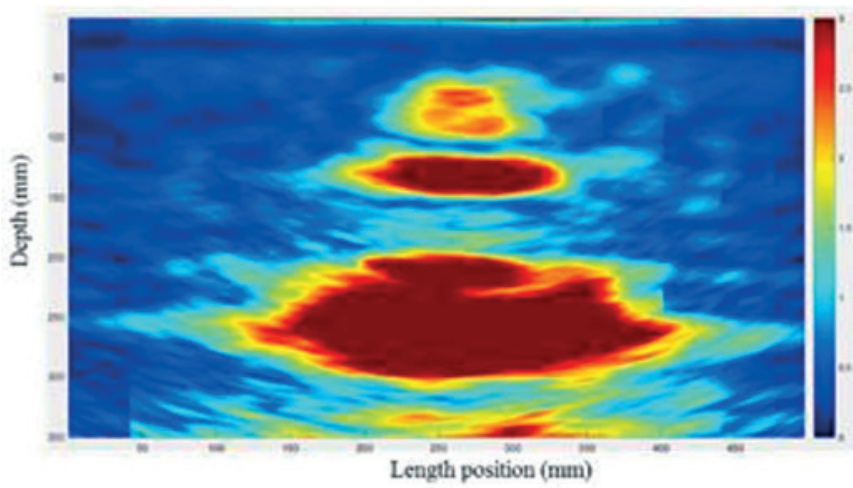

A

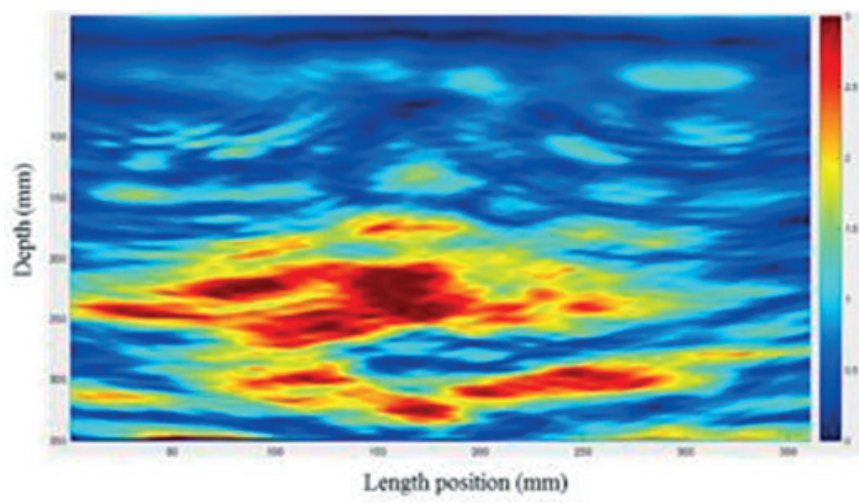

C

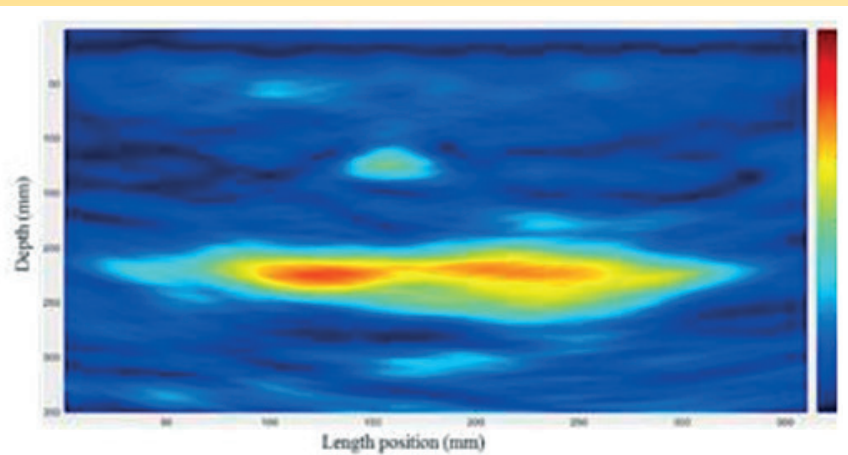

B

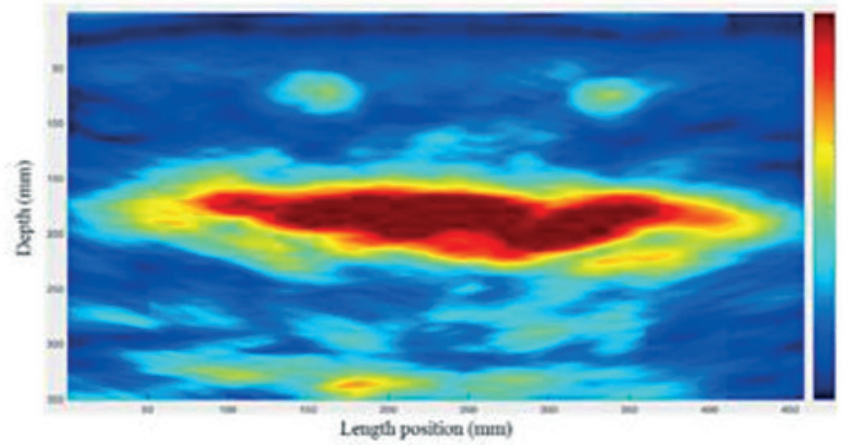

(D)

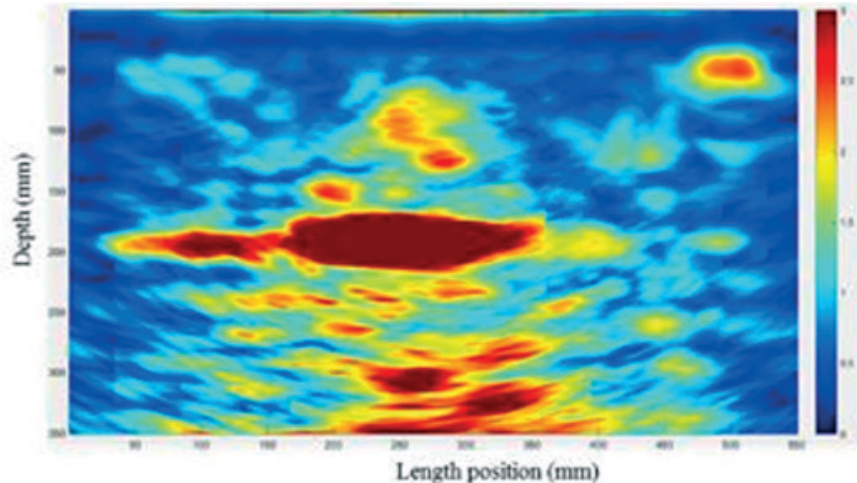

B

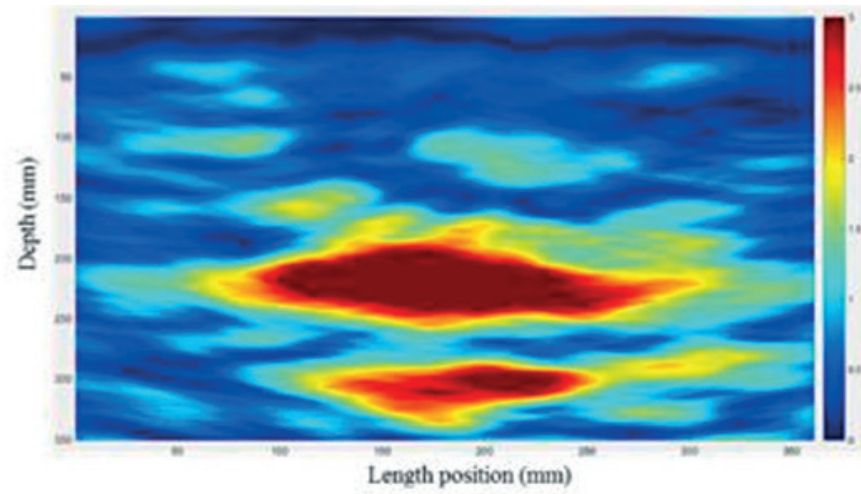

D

Figure 6

Reconstruction of distress locations presenting (a) and (b) cracks; and (c) and (d) ASR 
distresses reconstructions showed unexpected reflections through the concrete. Again, reflections below the interface are the result of the calibration material referent only to the first layer. However, the distress presence in the concrete makes these reflections more obvious in these cases.

\subsection{Concrete quality indicator}

Due to the unpredictable shape and depth of concrete pavement distresses, some reconstructions are not as clear as the ones presented in Figure 6. In order to address this issue, an ultrasonic signal quality index, the Hilbert Transform Indicator ( $\mathrm{HTI})$, was created. Figure 7 presents two cases on the same slab with their respective ultrasonic signals. The first case (Figure 7a) corresponds to a concrete without degradation where the ultrasonic signal has little amplitude variation. In the other hand, in Figure $7 \mathrm{~b}$ (location with surface indication of ASR), it is possible to observe several amplitude peaks indicating changes of material property (distress). The HTI values were 82 for the first case and 112 for the latter. It is also interesting to note that the mere B-Scan reconstruction would not necessarily inform about the distress presence as few mid-slab reflections show up in the second case, stressing the importance of a direct analysis of the ultrasonic signal. Table 1 shows the HTI value for reconstructions presented in Figures 3, 5 and 6. Note that the cases presented in Figure 6 (distresses) present HTI greater than 90 as expected. Values around 90 may be indicative of incipient distresses demonstrating the HTI ability to predict distresses not yet developed to the surface.

\section{Final considerations}

In order to fully investigate the potential of ultrasonic non-destructive evaluation for concrete pavements, a series of surveys was carried out in three experimental sections located at the University of São Paulo campus.

The ultrasonic device and the signal analysis methodology allowed thickness verification on three concrete slabs without causing any damage to the pavement. The forensic investigation (concrete specimens) at two locations proved the device's accuracy. Furthermore, considerations on the boundary condition of the ultra-thin whitetopping section were observed. Similarly, the methodology allowed the location of the longitudinal reinforcement in continuously reinforced concrete pavement (CRCP) section. For the CRCP, thickness below the designed one and misplaced reinforcement indicate serious construction problems.
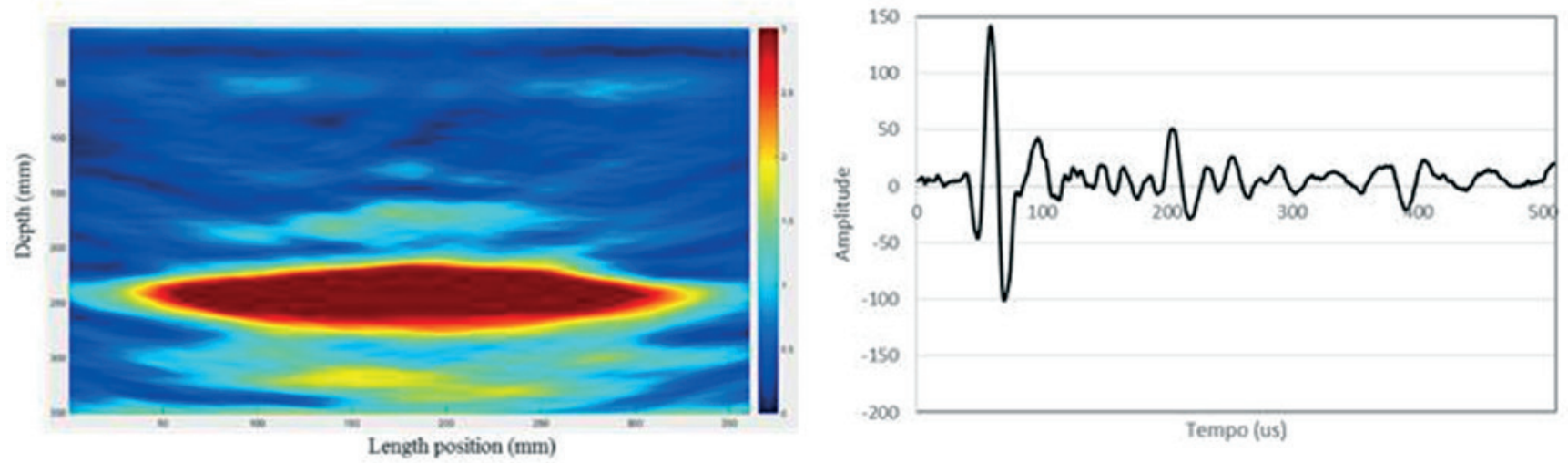

A
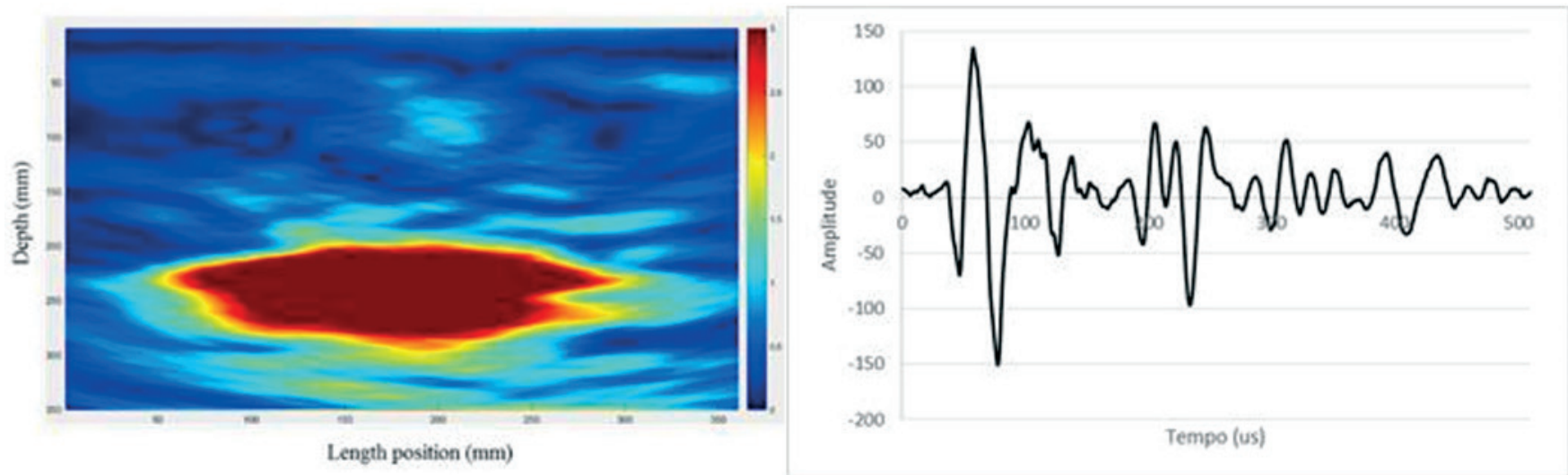

B

\section{Figure 7}

Differences in signal amplitude for sound (a) and damaged (b) concrete 
Table 1

Hilbert Transform Indicator (HTI) for the cases presented

\begin{tabular}{|c|c|c|}
\hline Case & $\begin{array}{c}\text { Concrete } \\
\text { pavement }\end{array}$ & HTI \\
\hline $3 a$ & JPCP & 86 \\
\hline $3 b$ & JPCP & 80 \\
\hline $3 c$ & UTW & 71 \\
\hline $3 d$ & UTW & 93 \\
\hline $3 e$ & CRCP & 72 \\
\hline $3 f$ & CRCP & 57 \\
\hline $5 a$ & CRCP & 67 \\
\hline $5 b$ & CRCP & 61 \\
\hline $5 c$ & CRCP & 70 \\
\hline $5 d$ & CRCP & 79 \\
\hline $6 a$ & CRCP & 103 \\
\hline $6 b$ & CRCP & 105 \\
\hline $6 c$ & JPCP & 113 \\
\hline $6 d$ & JPCP & 105 \\
\hline
\end{tabular}

Distresses like transverse cracks in the CRCP and alkali-silica reaction (ASR) in the jointed plain concrete pavement (JPCP) were observed thought unexpected mid-slab reflections (material changes) in the ultrasonic images reconstructions performed on the distress. However, only the image reconstruction analysis was not enough to suggest distress presence. Therefore, the technique of direct analysis of the ultrasonic signals was able to numerically differ between damaged and undamaged locations showing promise to predict distress before it reaches the slab surface.

\section{Acknowledgements}

The authors gratefully acknowledge the Coordenacão de Aperfeicoamento de Pessoal de Nível Superior (CAPES - Brazil Ministry of Education) for the scholarship granted to the first author through international program PDSE (Process - 99999.003858/2015-04).

\section{References}

[1] GROTE, K.; HUBBARD, S.; HARVEY, J.; RUBIN, Y. Evaluation of infiltration in layered pavements using surface GPR reflection techniques. Journal of Applied Geophysics, v. 57, 2005, p. $129-153$.

[2] HOEGH, K.; KHAZANOVICH, L.; YU, T. Concrete Pavement Joint Diagnostics with Ultrasonic Tomography. Transportation Research Record, v. 2305, 2012, p. 54 - 61.

[3] DANIELS, D. J. Surface-penetrating radar. ERA Technology, Institution of Electrical Engineers Radar Series no. 6, 1996, London.

[4] TOMPKINS, D. M.; KHAZANOVICH, L.; JOHNSON, D. Benefits of the Minnesota Road Research Project. Transportation Research Record, v. 2087, 2008, p. 12 - 19.
[5] HUGENSCHMIDT, J. Concrete bridge inspection with a mobile GPR system. Construction and Building Materials, v. 16, 2002, p. $147-154$.

[6] OLHOEFT, G. R.; SMITH III, S. S. Automatic Processing and Modeling of GPR data for Pavement Thickness and Properties. Proceedings of the 8th International Conference on Ground Penetrating Radar, 2000, Gold Coast, Australia.

[7] HUGENSCHMIDT, J.; MASTRANGELO, R. Concrete bridge inspection with a mobile GPR system. Cement \& Concrete Composites, v. 28, 2006, p. $384-392$.

[8] HAZA, A. O.; PETERSEN, C. G.; SAMOKRUTOV, A. Three Dimensional Imaging of Concrete Structures Using Ultrasonic Shear Waves. German Instruments SA, 2011, Denmark.

[9] MAIERHOFER, C. Nondestructive Evaluation of Concrete Infrastructure with Ground Penetrating Radar. Journal of Materials in Civil Engineering, v. 15, 2003, p. $287-297$.

[10] SCULLION, T. Using Rolling Deflectometer and Ground Penetrating Radar Technologies for Full Coverage Testing of Jointed Concrete Pavements. Report No FHWA-HIF-13-025, 2006, Federal Highway Administration.

[11] CLARK, M.R.; MCCANN, D. M.; FORDE, M. C. Application of infrared thermography to the non-destructive testing of concrete and masonry bridges. NDT \& E International, v. 36, 2003, p. $265-275$.

[12] PARK, J. H.; CHOI, M. Y.; KIM W. T. Infrared Thermography and Modeling to the Concrete Deck with Internal Defects as a Non-destructive Testing. Key Engineering Materials, v. 270-273, 2004, p. $938-943$.

[14] PRABHU, M..; BUCH, N.; VARMA, A. H.; THANDAVESWARA, D. Experimental Investigation of Effects of Dowel Misalignment on Joint Opening Behavior in Rigid Pavements. Transportation Research Record, v. 1947, 2006, p. $15-27$.

[13] HOEGH, K.; KHAZANOVICH, L. Correlation Analysis of 2D Tomographic Images for Flaw Detection in Pavements. ASTM Journal of Testing and Evaluation, v. 40, No, 2, 2012, p. $105-110$.

[15] NASIEF, H. G.; WHITED, G. C.; LOH, W. Y. Wisconsin Method for Probing Portland Cement Concrete Pavement for Thickness Statistical Comparison and Validation. Transportation Research Record, v. 2228, 2011, p. 99 - 107.

[16] HOSSAIN, S.; ELFINO, M. K. Field Demonstration of Magnetic Tomography Technology for Determination of Dowel Bar Position in Concrete Pavement. Report No FHWA/VTRC 06R40, 2006, Federal Highway Administration.

[17] PERLIN, L. P.; PINTO, R. C. A. Ultrasonic Tomography in Concrete. Ibracon Structures and Materials Journal, v. 6, n. 2, 2013, p. 246-269.

[18] CARBONARI, B. T.; CAVALARO, S. H.; CASTANHA, J. C. M; GUACELLI, P. A. G; SILVA, C. C. Utilization of the ultrasonic method to evaluate the properties of high performance concrete. Ibracon Structures and Materials Journal, v. 3, n.4, 2010, p. 494-511.

[19] DIOGENES, H. J. F; COSSOLINO, L. C.; PEREIRA, A. H. A.; DEBS, M. K. E; DELBS, A. L. H. Determination of modulus of elasticity of concrete from the acoustic response. Ibracon Structures and Materials Journal, v. 4, n. 5, 2011, p. 792-813. 
[20] HOEGH, K.; KHAZANOVICH, L.; YU, T. Ultrasonic Tomography for Evaluation of Concrete Pavements. Transportation Research Record, v. 2232, 2011, p. 85 - 94.

[21] VANCURA, M.; KHAZANOVICH, L.; BARNES, R. Concrete Pavement Thickness Variation Assessment with Cores and Nondestructive Testing Measurements. Transportation Research Record, v. 2347, 2013, p. $61-68$.

[22] HOEGH, K.; KHAZANOVICH, L.; WOREL, B. J.; YU, T. Detection of Subsurface Joint Deterioration Blind Test Comparison of Ultrasound Array Technology with Conventional Nondestructive Methods. Transportation Research Record, v. 2367, 2013, p. $3-12$.

[23] HOEGH, K.; KHAZANOVICH, L. Extended synthetic aperture focusing technique for ultrasonic imaging of concrete. NDT \& E International, v. 74, 2015, p. $33-42$.

[24] FREESEMAN, K.; HOEGH, K.; KHAZANOVICH, L. Characterization of Concrete at Various Freeze-Thaw Damage Conditions Using SH-Waves. Proceedings of the 42nd Review of Progress in Quantitative Nondestructive Evaluation (QNDE), 2015, Minneapolis.

[25] DWIGHT, C.; KHAZANOVICH, L.; SALLES, L. Linear Array Ultrasonic Test Results from Alkali-Silica Reaction (ASR) Specimens. Report No ORNL/TM-2016/159. Oak Ridge National Laboratory. Electrical and Electronics Systems Research Division, 2016, US Department of Energy, Washington, D.C.

[26] BALBO, J. T.; SEVERI, A. A. Thermal gradients in concrete pavements in tropical environment. Experimental appraisal. Transportation Research Record, v. 1809, 2002, p. 12 - 22.

[27] BALBO, J. T.; PEREIRA, D. S. Gradientes Térmicos em Whitetopping Ultradelgado na Pista Experimental Instrumentada da USP. [in portuguese]. Transportes, Rio de Janeiro, v. 9, n.1, 2001, p. 69-87.

[28] SALLES, L. S.; BALBO, J. T. Experimental continuously reinforced concrete pavement parameterization using nondestructive methods. Ibracon Structures and Materials Journal, v. 9, 2016, p. 263-274.

[29] HOEGH, K.; KHAZANOVICH, L.; MASER, K. TRAN, N. Evaluation of Ultrasonic Technique for Detecting Delamination in Asphalt Pavements. Transportation Research Record, v. 2306, 2012, p. $105-110$.

[30] EDWARDS, L. Evaluation of Technologies for Nondestructively Determining Concrete Pavement Thickness. Proceedings of the 10th International Conference on Concrete Pavement, ISCP, 2012, Québec City, Canada. 